\title{
Correction to: Patterns of Local Autonomy in Europe
}

\section{Correction to:}

\author{
A. Ladner et al., Patterns of Local Autonomy in Europe, Governance \\ and Public Management, \\ https://doi.org/10.1007/978-3-319-95642-8
}

This book was inadvertently published without updating the author corrections in chapters $1,2,3,4,5,6,7,8,9,12,13$ and 14 . The corrections have been updated in the respective chapters.

\footnotetext{
The updated online versions of the chapters can be found at https://doi.org/10.1007/978-3-319-95642-8_1 https://doi.org/10.1007/978-3-319-95642-8_2 https://doi.org/10.1007/978-3-319-95642-8_3 https://doi.org/10.1007/978-3-319-95642-8_4 https://doi.org/10.1007/978-3-319-95642-8_5 https://doi.org/10.1007/978-3-319-95642-8_6 https://doi.org/10.1007/978-3-319-95642-8_7 https://doi.org/10.1007/978-3-319-95642-8_8 https://doi.org/10.1007/978-3-319-95642-8_9 https://doi.org/10.1007/978-3-319-95642-8_12 https://doi.org/10.1007/978-3-319-95642-8_13 https://doi.org/10.1007/978-3-319-95642-8_14
}

(C) The Author(s) 2019

A. Ladner et al., Patterns of Local Autonomy in Europe, Governance and Public Management, https://doi.org/10.1007/978-3-319-95642-8_15 